\title{
INVESTIGATION OF CRACKING SUSCEPTIBILITY OF AUSTENITIC MATERIAL USING PVR-TEST PROCEDURE
}

\author{
K.A. YUSHCHENKO, V.S. SAVCHENKO, N.O. CHERVYAKOV, \\ A.V. ZVYAGINTSEVA, G.G. MONKO and V.A. PESTOV \\ E.O. Paton Electric Welding Institute, NASU
}

11 Bozhenko Str., 03680, Kiev, Ukraine. E-mail: office@paton.kiev.ua

\begin{abstract}
Comparative investigation of hot cracking sensitivity of commercial welding wires has been performed. It is shown that an all-purpose method of weldability evaluation can be the machine method with controllable forced deformation during TIG welding (PVR-test method), which allows separating the conditions of initiation of solidification cracks and ductility dip cracks in the weld and HAZ metal, and provides comprehensive information about quantitative characteristics of cracking sensitivity. 6 Ref., 9 Figures.
\end{abstract}

$\boldsymbol{K} \boldsymbol{e} \boldsymbol{y} \boldsymbol{w} \boldsymbol{o} \boldsymbol{r} \boldsymbol{d} \boldsymbol{s}:$ weldability, hot cracks, crack resistance evaluation, high-alloyed steels, nickel alloys

Austenitic high-alloyed steels and their welded joints are rather sensitive to hot cracking. Their sensitivity is abruptly increased in fusion welding of stably austenitic steels and nickel alloys, which preserve face-centered cubic lattice in the entire temperature range. Considering the complexity of thermodeformational processes, taking place in fusion welding of the above materials and diversity of the kinds of initiating cracks, evaluation of material sensitivity to cracking and their classification are an urgent problem. Valuable information about hot cracking sensitivity can only be obtained in the case, when practically all the crack types are studied in one sample during one experiment.

In this case external influence during sample realization is the same for all the zones of the studied sample, however, having different formation mechanisms, different kinds of cracks develop non-simultaneously, thus determining the priorities at evaluation of crack resistance of the joint as a whole.

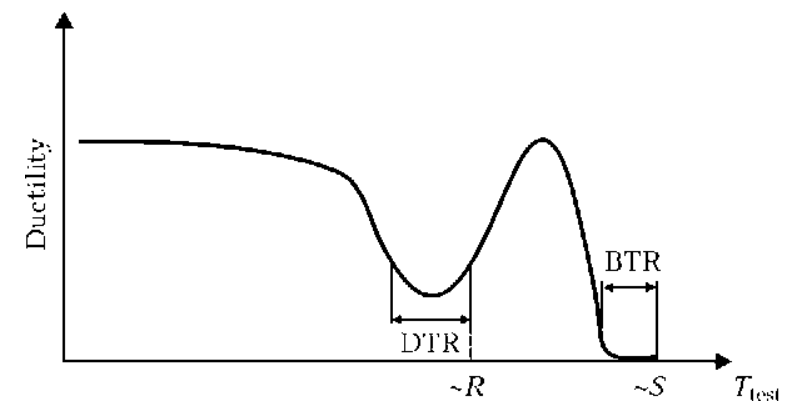

Figure 1. Hot cracking in welded joints of high-alloyed steels and alloys: $R$ - recrystallization [2]
According to international standard ISO 17641-1:2004 hot cracks are violations of material integrity, formed at high temperature along grain boundaries (dendrite boundaries), when deformation or strain rate exceed a certain level. In their turn, cracks are subdivided into solidification, liquation and ductility dip cracks [1]. Causes for cracking are numerous, but usually they initiate, when local ductility is insufficient to counteract the developing welding deformations. Exact mechanism of hot crack initiation has not yet been clarified.

Temperature interval of solidification crack initiation (BTR) depends on the range of the metal solid-liquid state at weld solidification. Lower boundary of this range is determined by the value of solidus temperature $T_{S}$ when solidification is over. Temperature range of ductility dip (DTR) is determined by approximate ratio of $(0.6-0.8) T_{S}$ (Figure 1). In this temperature

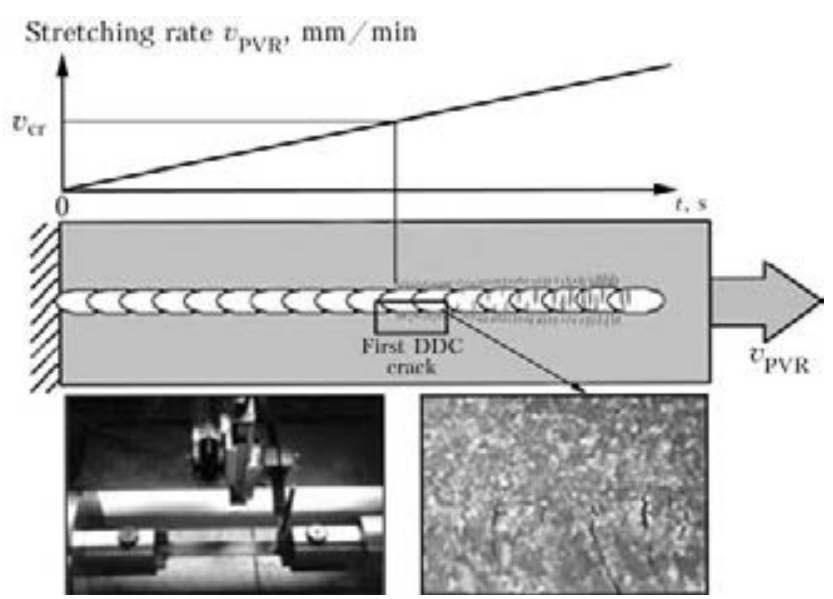

Figure 2. Testing schematic at application of PVR-test method [6] 


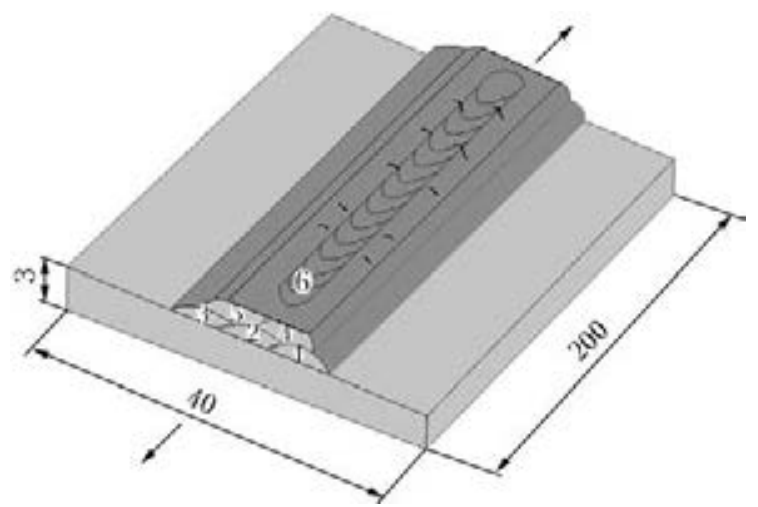

Figure 3. Schematic of conducting an experiment on evaluation of crack resistance of metal of welds with stably austenitic structure: 1-5 - sequence of weld performance when making a sample by TIG welding with filler wire; 6 - control weld with simultaneous forced deformation (TIG without filler); arrows - direction of forced deformation

range cracks initiate and propagate along the boundaries of high-angle austenitic grains.

There exist numerous procedures for determination of hot cracking sensitivity [3, 4]. According to standard ISO 17641-1:2004, testing for hot cracking sensitivity is subdivided into two main groups: testing with natural rigidity and testing with external load application. PVR-test belongs to the second testing group, alongside MVT-test and hot tensile testing.

According to ISO 17641-3:2005, this method is applicable for evaluation of weldability of structural materials during performance of single- and multipass welding of austenitic corrosion-resistant steels, nickel-base alloys and nickel-copper alloys. It, however, can be also applied for other materials, such as aluminium alloys and high-strength steels [5].

This evaluation method is realized by performance of nonconsumable-electrode welding without filler along the plate central axis with simultaneous longitudinal deformation of the sample, changing in time.

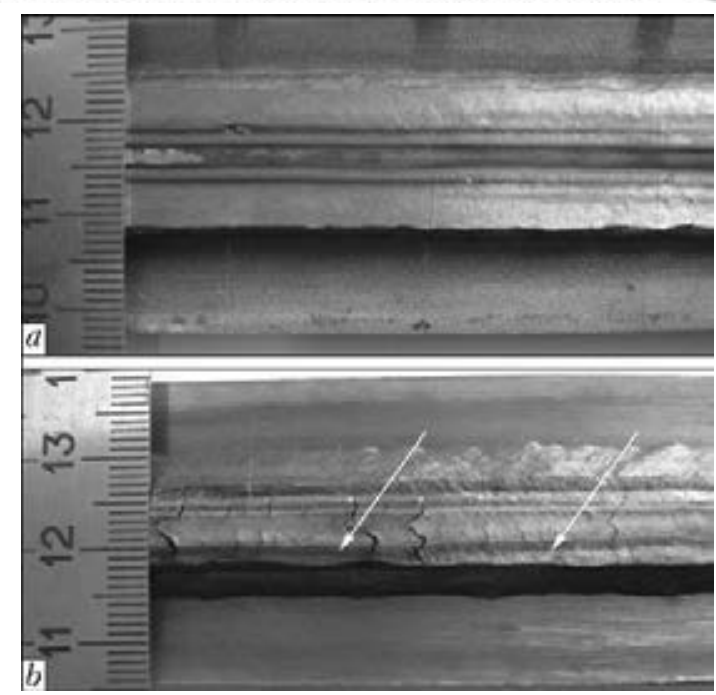

Figure 4. General view of sample surface after testing by PVR-procedure: $a$ - welding wire Sv-06Kh18N10; $b-$ EP-690; arrows show hot cracks

Critical strain rate $v_{\text {cr }}$, at which first cracks appear, was selected as the criterion of cracking sensitivity (Figure 2). During welding performance cracks can initiate simultaneously both in the weld metal, and in the HAZ metal [6]. These cracks, as a rule, appear at different $v_{\mathrm{cr}}$. This allows quantitative characterization of sensitivity to a certain crack type. More accurate information about the moment of cracking initiation can be derived by studying weld surface with application of optical methods of magnification.

The objective of his work was investigation of hot cracking sensitivity of commercial welding wires by PVR-test method.

Sv-06Kh18N10 wire is used for welding of structures from general purpose high-alloyed steels, and it provides a certain amount of $\delta$-ferrite in welds, which counteracts hot crack initiation.

EP-690 wire is recommended for welding structures from austenitic steels with stably austenitic structure. $\delta$-ferrite, which in some cases is an undesirable component because of met-

Table 1. Chemical composition of studied welding wires, wt.\%

\begin{tabular}{||l|c|c|c|c|c|c|c|c|c||}
\hline \multicolumn{1}{|c|}{ Wire grade } & $\mathrm{C}$ & $\mathrm{Si}$ & $\mathrm{Mn}$ & $\mathrm{Cr}$ & $\mathrm{Ni}$ & $\mathrm{Mo}$ & $\mathrm{N}$ & $\mathrm{S}$ & $\mathrm{P}$ \\
\hline $\begin{array}{l}\text { Sv-06Kh18N10 } \\
\text { (GOST 2646-70) }\end{array}$ & 0.05 & 0.7 & 1.5 & 19.1 & 10.1 & - & - & $<0.02$ & $<0.02$ \\
\hline EP-690 & $\geq 0.03$ & 0.5 & 9.8 & 18.2 & 14.1 & 2.5 & 0.06 & $<0.02$ & $<0.02$ \\
\hline
\end{tabular}

Table 2. Chemical composition of high-chromium nickel-base welding consumables, wt.\%

\begin{tabular}{||l|c|c|c|c|c|c|c|c|c|c|c|c||}
\hline \multicolumn{1}{|c|}{ Material grade } & $\mathrm{C}$ & $\mathrm{Mn}$ & $\mathrm{Ni}$ & $\mathrm{Cr}$ & $\mathrm{Fe}$ & $\mathrm{Nb}$ & $\mathrm{Mo}$ & $\mathrm{Ti}$ & $\mathrm{S}$ & $\mathrm{P}$ & $\mathrm{Al}$ & $\mathrm{Si}$ \\
\hline Inconel 690 & 0.025 & 0.24 & Base & 29.72 & 10.3 & - & - & 0.28 & 0.002 & 0.005 & 0.87 & 0.32 \\
\hline Inconel 52 & 0.026 & 0.31 & Same & 28.80 & 8.5 & 0.03 & 0.03 & 0.51 & 0.001 & 0.004 & 0.72 & 0.12 \\
\hline Inconel 52MSS & 0.024 & 0.29 & $\gg$ & 30.30 & 7.2 & 2.52 & 3.51 & 0.25 & 0.0008 & 0.0006 & 0.22 & 0.15 \\
\hline
\end{tabular}




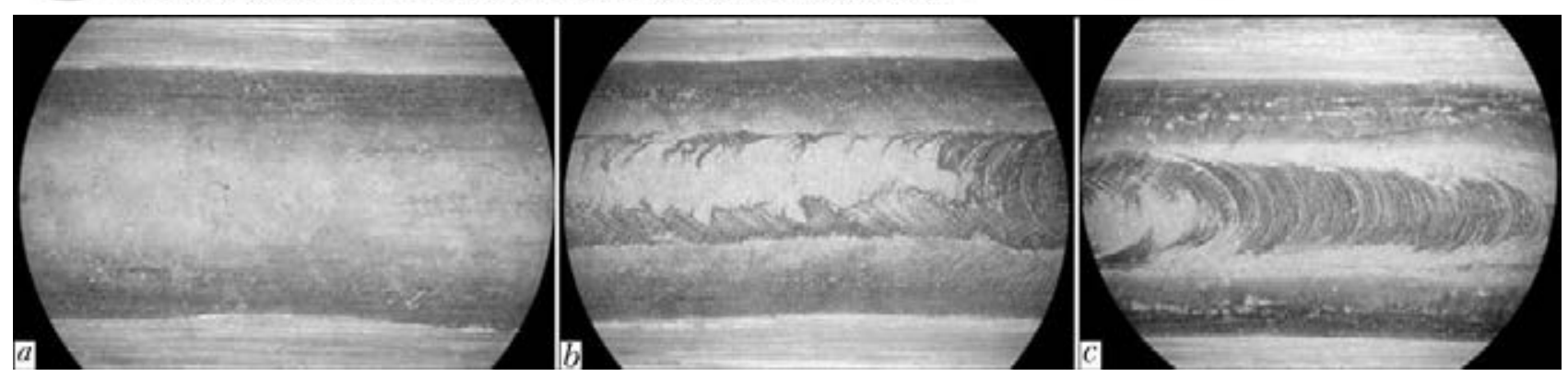

Figure 5. Fragments of surface of welds $(\times 50)$ made by Sv-06Kh18N10 wire at testing with application of PVR-method at forced strain rate: $a-2 ; b-8 ; c-12 \mathrm{~mm} / \mathrm{h}$; arrows show ductility dip cracks

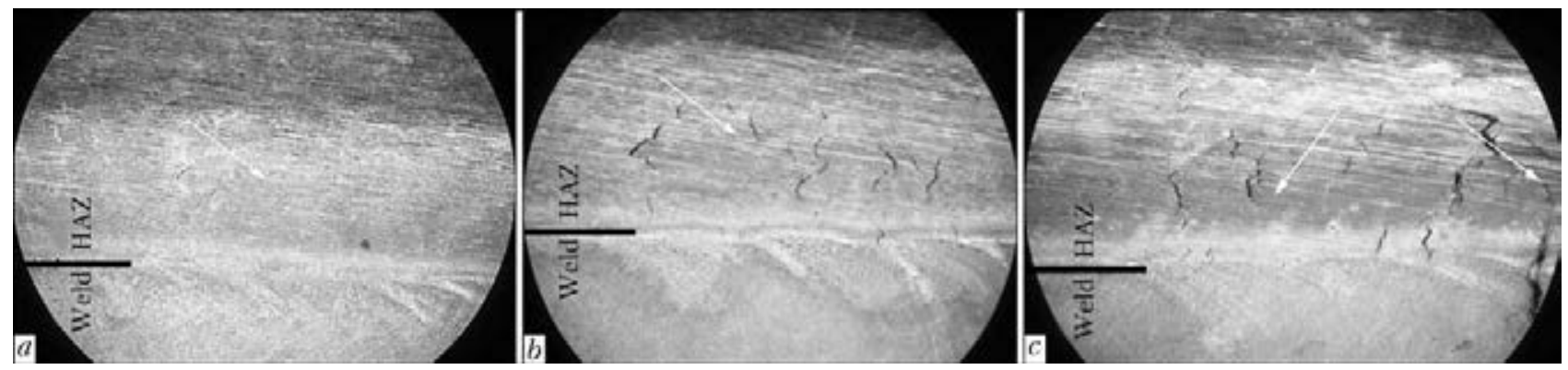

Figure 6. Fragments of surface of welds $(\times 50)$ made with EP-690 wire at testing with application of PVR-method at forced strain rate: $a-2 ; b-8 ; c-12 \mathrm{~mm} / \mathrm{min}$; arrows show ductility dip cracks

al embrittlement in service, is absent in the weld composition. In this case, sufficient crack resistance in welding should be achieved by further alloying of welds by such elements as manganese, molybdenum and nitrogen.

Composition of welding wires is given in Table 1 .

Also studied were high-chromium nickel-base filler materials of the type of Inconel 690 alloy, which are widely used in manufacture of components of nuclear power plants (Table 2). Kinetics of the influence of molybdenum and niobium, additionally alloying Inconel 52MSS wire, on hot cracking sensitivity was studied.

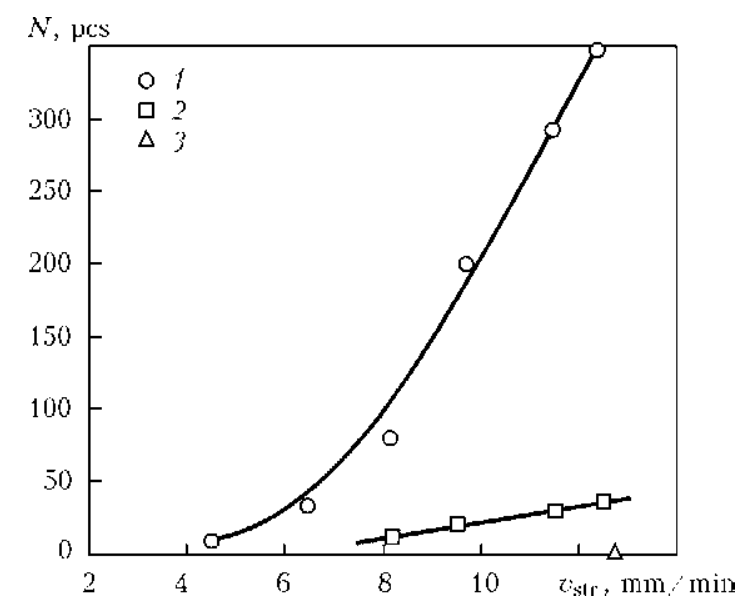

Figure 7. Dependence of number of hot cracks in the metal of welds studied using PVR-test method, which have stably austenitic structure: 1,2- ductility dip cracks and solidification cracks, respectively (EP-690 wire); 3 - no cracks (Sv-06Kh18N10)
Samples were made using stably austenitic high-alloyed Kh20N16AG6 steel, on which beads were deposited by welding wires Sv-06Kh18N10 and EP-690, as well as nickel alloy Inconel 690, on which multilayered beads were deposited by Inconel 52 and Inconel 52MSS wires.

Schematic of bead deposition to produce samples at forced loading, according to PVR-test procedure, is given in Figure 3.

Control weld was made by TIG welding without filler in the following mode: $I_{\mathrm{w}}=60 \mathrm{~A} ; U_{\mathrm{a}}=$ $=9.5 \mathrm{~V} ; v_{\mathrm{w}}=7.2 \mathrm{~m} / \mathrm{h}$.

Welding with simultaneous deformation of the sample was performed in FP100/1 rupture machine with rigid loading system. During testing loading at sample deformation is recorded, as well as the extent and speed of sample grip displacement.

Analysis of the surface of welds, made with Sv-06Kh18N10 wire, showed complete absence of hot cracks in the metal of the control weld and HAZ, when making the control weld (Figures 4, $a$ and 5). Thus, a conclusion can be made that chromium-nickel high-alloyed welds, made with Sv-06Kh18N10 wire, are not susceptible either to solidification cracks, or to ductility dip cracks.

Investigation of the surface of welds made with EP-690 wire showed that hot cracks initiate in the metal of welds and HAZ of the control weld, particularly at high values of strain rate (Figure 6), crack number increasing with increase of strain rate (Figure 7). Considering that 


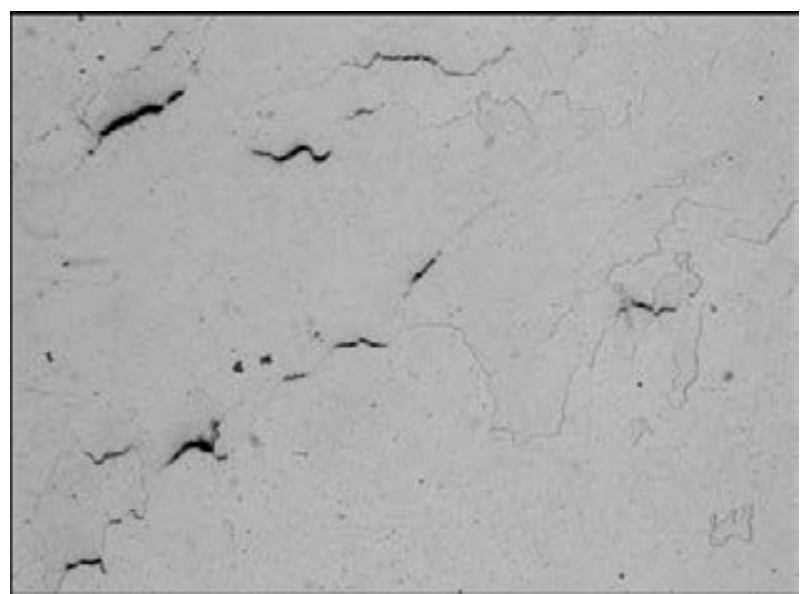

Figure 8. Microstructure $(\times 100)$ of weld with ductility dip cracks

cracking susceptibility is proportional to the number of cracks, which initiated in welding by PVR-test procedure, it can be assumed that the studied welded joints should be the most sensitive to initiation of ductility dip cracks (Figure 8).

Data generalization by the results of testing welds made with high-chromium consumables (Figure 9) shows that welds, made with Inconel 52 welding wire with stably austenitic structure, are sensitive to formation of ductility dip cracks, initiating in HAZ, particularly, when making multipass welds. On the other hand, additional alloying of welds by niobium and molybdenum (Inconel 52MSS wire) leads to an abrupt reduction of the number of cracks. Thus, additional alloying of stably austenitic welds by molybdenum and niobium is an effective method of improvement of nickel alloy weldability.

\section{Conclusions}

1. Machine method with adjustable forced deformation during TIG welding (PVR-test) can be a versatile method of weldability evaluation. This method allows separating the conditions of development of solidification and ductility dip cracks, as well as obtaining exhaustive information on quantitative characteristics of cracking sensitivity.

2. The main type of cracks in welding of abovementioned materials by modern welding wires with reduced quantity of impurity elements are not solidification cracks, but ductility dip cracks.

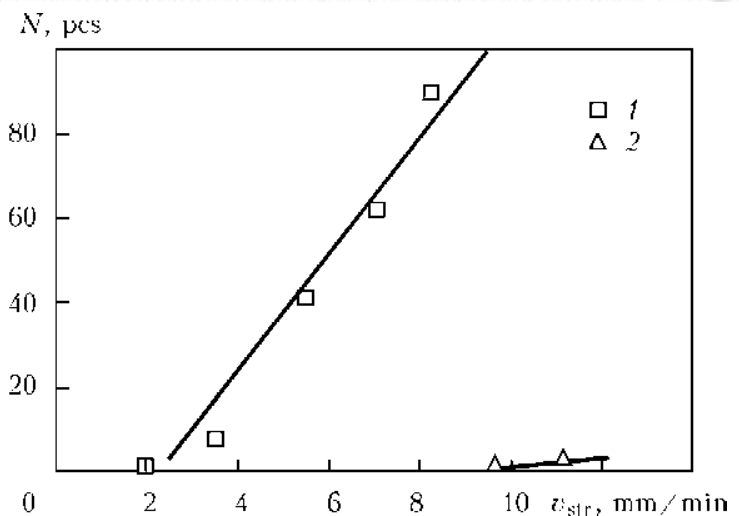

Figure 9. Number of ductility dip cracks in metal of welds, studied using PVR-test method, made with welding wire Inconel 52 (1) and Inconel 52MSS (2)

3. It is confirmed that presence of $\delta$-ferrite is a cardinal method of hot cracking prevention. In the case, when such a method cannot be used because of service conditions of welded joints, it is rational to additionally alloy the welds by elements which change thermodeformational conditions in welding, and thus prevent cracking.

4. Welds with $\mathrm{Ni}-\mathrm{Cr}-\mathrm{Fe}$ basic alloying system are susceptible to ductility dip cracking. On the other hand, additional alloying of welds by niobium and molybdenum leads to considerable reduction of the number of ductility dip cracks in multipass welding.

1. ISO 17641-1:2004: Destructive tests on welds in metallic materials. Hot cracking tests for weldments. Arc welding processes. Pt 1: General.

2. Hemsworth, W., Boniszewski, T., Eaton, N.F. (1969) Classification and definition of high temperature welding cracks in alloys. Metal Constr. and British Welding J., 1(25), 5-16.

3. Lippold, J.C., Kotecki, D.J. (2005) Welding metallurgy and weldability of stainless steels. Jonh Wiley\&Sons.

4. Derlomenko, V.V., Yushchenko, K.A., Savchenko, V.S. et al. (2010) Technological strength and analysis of causes of weldability deterioration and cracking. The Paton Welding J., 9, 20-23.

5. ISO/TR 17641-3:2005: Destructive tests on welds in metallic materials. Hot cracking tests for weldments. Arc welding processes. Pt 3: Externally loaded tests.

6. Herold, H., Streitenberger, M., Pchennikov, A. (2000) Modelling of the PVR-test to examine the origin of different hot cracking types. II W Doc. $I X^{-}$ $H-474-00$.

Received 11.04.2014 